\title{
Serial position effects in immediate and final recall as a function of test anxiety and sex
}

\author{
PATRICIA E. BROWER and JOHN H. MUELLER \\ University of Missouri, Columbia, Missouri 65201
}

\begin{abstract}
Subjects differing in test anxiety had a single immediate free recall test on each of eight unrelated 12-item lists, followed by final free recall for all items from all lists. There were no main effects due to test anxiety, but Anxiety by Sex interactions indicated that, while high anxiety was generally associated with worse performance than low anxiety for males, it was generally associated with better performance for females. There was little difference between males and females at low-anxiety levels, but females performed better than males given high anxiety.
\end{abstract}

Recent research has shown that free recall performance is hindered by high test anxiety (e.g., Mueller, Carlomusto, \& Marler, 1977). One explanation of this deficit is reduced cue utilization (cf. Easterbrook, 1959; Kausler \& Trapp, 1960), in that word features that could aid recall are not encoded (Eysenck, 1977; Mueller, 1976). It is possible to view this cue-utilization deficit in terms of the levels-of-processing framework for memory research (Craik \& Lockhart, 1972). "Shallow" processing involves encoding physical features of the stimulus, while "deep" processing involves semantic content. Retention is said to improve when deeper processing occurs, or when rehearsal "elaborates" the memory trace rather than merely "maintaining" it (Craik \& Tulving, 1975). Previous research, using categorized free recall lists, has shown that high-anxiety subjects perform worse than low-anxiety subjects for both semantic and nonsemantic relationships (e.g., Mueller et al., 1977).

The present experiment extended this line of inquiry to the depth analysis of serial position effects in immediate and final free recall of unrelated items. It is typically found that the probability of immediate recall varies as a function of input position, with last-presented (recency) items having a higher probability of recall than items from earlier positions, at least for practiced subjects. However, if the recall test is given after several (unrelated) interpolated lists, then recency items are not recalled as well as earlier items, and may even show reduced recall relative to earlier items, a result known as "negative recency." This pattern of results is explained by arguing that subjects learn they can maximize immediate recall by superficially processing last-presented items, since these encodings will suffice for early recall on the immediate test. Shallow encodings presumably

Requests for reprints should be sent to J. H. Mueller, Psychology Department, 210 McAlester Hall, University of Missouri, Columbia, Missouri 65201. are lost rapidly though, so when the final delayed test occurs, recency items are poorly recalled.

The depth analysis of the anxiety deficit suggests that primacy-recency effects might differ for high- and lowanxiety subjects. If the anxiety deficit is limited to deep processing, and if the recency items are not processed deeply, then the anxiety deficit should be more apparent for primacy and middle items than for recency items. However, if this deficit includes both deep and shallow processing, then the deficit should be as apparent for recency items as for earlier items. The present experiment examined this question.

\section{METHOD}

\section{Subjects and Design}

Thirty-six students from introductory psychology classes participated; high-anxiety subjects had scores above 20 on Sarason's (1972) test-anxiety scale, while low-anxiety subjects had scores below 13. The design was a 2 by 2 factorial for anxiety and sex. Mean test-anxiety scores were comparable for highanxiety males and females (25.0 and 29.6, respectively) and for low-anxiety males and females (12.2 and 11.4).

\section{Procedure}

Eight 12-item lists were constructed from 96 unrelated, highimagery, high-frequency nouns selected from the Paivio, Yuille, and Madigan (1968) norms. Interitem associations were screened in word association norms.

Subjects were tested individually or in pairs. The words were presented by a slide projector at a 3-sec rate. Subjects pronounced each word aloud as it was shown. A 60-sec written test immediately followed the last item in each list. The instructions emphasized the option of recalling in any order, but did not mention the delayed test. There were no special ego-involving statements in the general instructions.

After the eighth immediate test, subjects were required to count backward by threes from a three-digit number for $15 \mathrm{sec}$. They were then given $8 \mathrm{~min}$ to write down as many of the words as they could remember from all of the lists.

\section{RESULTS AND DISCUSSION}

Primacy recall was scored by considering only items recalled from the first two positions, recency recall was 
defined as items recalled from the last two positions, and middle recall refers to items from Positions 5-8. The mean probability of recall for each segment is shown in Table 1, pooled over all eight lists. On the immediate tests, recall from short-term storage was identified using the technique developed by Tulving and Colotla (1970), where an item is defined as having come from short-term store if seven or fewer input-output events occur between presentation and recall. This was analyzed in terms of the absolute number of such items, as well as the proportion of total recall that came from short-term store. In the final recall data, the difference between mean recall for middle and recency items was computed as an index of "negative" recency.

Test anxiety was not significant ${ }^{1}$ as a main effect for any of the measures $(\mathrm{Fs}<1.56)$. There were, however, a number of interactions of Anxiety by Sex. Generally, high anxiety hindered males, relative to low anxiety, but high anxiety facilitated the performance of females. The interaction was significant in immediate recall for primacy items $(F=6.03$, MSe $=.011)$, middle items $(\mathrm{F}=9.46, \mathrm{MSe}=.011)$, and recency items $(\mathrm{F}=7.13$, MSe $=.013)$, but nonsignificant for the two shortterm store measures $(\mathrm{Fs}<1)$. The interaction was significant on the final test for the recall of middle items $(F=7.79, \mathrm{MSe}=.013)$, and for the negative recency difference score $(\mathrm{F}=4.89, \mathrm{MSe}=.018)$, but not for primacy or recency items (Fs $<1)$.

For the immediate-test data, individual comparisons (1.s.d.) revealed that high-anxiety males recalled significantly $(p<.05)$ fewer recency items than low-anxiety males, but there was no significant high-anxiety deficit for middle or primacy items. High-anxiety females recalled significantly more items than low-anxiety females for all three segments. For final recall, highanxiety males were significantly worse than low-anxiety males only for middle items and the difference score, while high- and low-anxiety females were statistically comparable for all segments and the difference score.

These results at best only partially support a levels-

Table 1

Average Probability of Recall for Each Input Segment by Test Anxiety and Sex, Pooled Over Eight Lists

\begin{tabular}{lrcccr}
\hline & \multicolumn{2}{c}{ High } & & \multicolumn{2}{c}{ Low } \\
\cline { 2 - 3 } \cline { 5 - 6 } & Male & Female & Male & Female \\
\hline & \multicolumn{4}{c}{ Immediate } & Recall \\
Primacy & .63 & .76 & .69 & .64 \\
Middle & .43 & .62 & .51 & .48 \\
Recency & .62 & .68 & .71 & .56 \\
STS-Number & 2.59 & 2.50 & 2.81 & 2.20 \\
STS-Proportion & .26 & .19 & .24 & .21 \\
& & Final Recall & \\
Primacy & .38 & .51 & .44 & .47 \\
Middle & .24 & .44 & .35 & .34 \\
Recency & .20 & .20 & .17 & .15 \\
Difference & -.04 & -.24 & -.18 & -.19 \\
\hline
\end{tabular}

Note-STS refers to recall from short-term storage. of-processing analysis of the high-anxiety performance deficit. The depth analysis generally held for males in final recall; that is, high anxiety was worse than low anxiety for primacy and middle items and not for recency items, but the depth prediction was not supported for females in final recall. The predictions were not supported for either sex in immediate recall.

There was no deficit for short-term store items, words that could be viewed as shallowly processed by all subjects. This seems somewhat at variance with the results of Mueller and Overcast (1976), who found highanxiety subjects recalled more from short-term storage than low-anxiety subjects. However, the lists were shorter here, and the present study used only a single test per list instead of multiple trials with the same list as in the Mueller and Overcast study. Like the earlier study though, these results show some discrepancy between conclusions based on simple recency recall and short-term store recall, apparently due to the outputorder priority component in the latter that is not involved in the former.

The absence of an anxiety difference on a delayed test is not uncommon (e.g., Mueller \& Overcast, 1976). This outcome is not consistent with a depth analysis, which would expect shallowly encoding high-anxiety subjects to do worse than low-anxiety subjects, nor is it consistent with an analogy involving the arousalconsolidation hypothesis of long-term superiority for high-anxiety subjects (cf. Eysenck, 1977).

An interesting finding was the Anxiety by Sex interaction for several measures, but any explanation of this must be post hoc. One possibility follows from the assumption that test anxiety involves two components, (a) worry, which has a detrimental effect on performance, and (b) emotionality, which may have a positive effect (Spielberger, Gonzalez, Taylor, Algaze, \& Anton, 1978). If females were relatively higher than males on emotionality, then the present results would perhaps be interpretable. There is some indication that females score higher than males on both subscales, but more so for the emotionality subscale (Spielberger et al., 1978), in accord with this interpretation. This subscale information was not available for the present subjects, but this possibility may warrant further consideration in subject selection and analyses in future test-anxiety research. It is also possible that females have greater verbal fluency in general than males; if so, recall of verbal materials might constitute an "easy" task in drive theory terms, with the expectation of improved performance given high anxiety (cf. Eysenck, 1977). These are mentioned only as speculations at this point, and other factors may be involved (cf. Maccoby \& Jacklin, 1974).

\section{REFERENCES}

Craik, F. I. M., \& Lockrart, R. S. Levels of processing: A framework for memory research. Journal of Verbal Learning and Verbal Behavior, 1972, 11, 671-684. 
Craik, F. I. M., \& Tulving, E. Depth of processing and the retention of words in episodic memory. Journal of Experimental Psychology: General, 1975, 1, 268-294.

Easterbrook, J. A. The effect of emotion on cue utilization and the organization of behavior. Psychological Review, 1959, 66, 183-201.

Eysenck, M. W. Human memory: Theory, research and individual differences. Oxford: Pergamon Press, 1977.

KaUsler, D. H., \& TRAPP, E. P. Motivation and cue utilization in intentional and incidental learning. Psychological Review, 1960, 67, 373-379.

MaccoBy, E. M., \& JACKIIN, C. N. The psychology of sex differences. Stanford, Calif: Stanford University Press, 1974.

Mueller, J. H. Anxiety and cue utilization in human learning and memory. In M. Zuckerman \& C. D. Spielberger (Eds.), Emotions and anxiety: New concepts, methods and applications. Hillsdale, N.J: Lawrence Erlbaum, 1976.

Mueller, J. H., Carlomusto, M., \& Marler, M. Recall as a function of method of presentation and individual differences in test anxiety. Bulletin of the Psychonomic Society, 1977, 10, 447-450.

Mueller, J. H., \& Overcast, T. D. Free recall as a function of test anxiety, concreteness, and instructions. Bulletin of the Psychonomic Society, 1976, 8, 194-196.
Paivio, A., Yuille, J. C., \& Madigan, S. Concreteness, imagery, and meaningfulness values for 925 nouns. Journal of Experimental Psychology Monograph, 1968, 76(1, Part 2).

SARASON, I. G. Experimental approaches to test anxiety: Attention and the uses of information. In C. D. Spielberger (Ed.), Anxiety: Current trends in theory and research (Vol. 2). New York: Academic Press, 1972.

SPIelberger, C. D., Gonzalez, H. P., TAYlor, C. J., Algaze, B., \& Anton, W. D. Examination stress and test anxiety. In C. D. Spielberger \& I. G. Sarason (Eds.), Anxiety and stress (Vol. 5). New York: Hemisphere/ Wiley, 1978.

Tulving, E., \& Colotla, V. A. Free recall of trilingual lists. Cognitive Psychology, 1970, 1, 86-98.

\section{NOTE}

1. Effects described as significant involve $p<.05$ or better. All Fs have 1 and 32 degrees of freedom.

(Received for publication March 31, 1978.) 